\title{
Maisie: el sujeto del inconsciente más allá del niño
}

\author{
What Maisie Knew | Scott Mc Gehee, David Siegel | 2012
}

\author{
Valeria Nuñez* \\ Universidad de la Cuenca del Plata, Universidad Católica de las Misiones
}

Recibido: 1 de marzo 2017; aceptado: 13 de mayo 2017

\begin{abstract}
Resumen
Una niña de 6 años, una separación conflictiva, y una guerra en la que todo vale para sostener el narcisismo propio. Hasta ahí tenemos un coctel que resulta ser moneda corriente en estos tiempos. Sin embargo, los directores permiten ver, para quien decide no quedarse con el clisé de los padres que traumatizan al niño, la posibilidad de invención del sujeto-niño, de aquel que en términos de Lacan se posiciona y hace algo con el real que le tocó en suerte. En este pequeño ensayo, se intentará no sólo considerar las dificultades que para el psiquismo infantil implican la carencia en la significación por parte del Otro, sino también la posición que el niño asume en tanto sujeto de pleno derecho para hacerse un lugar en el Otro.
\end{abstract}

Palabras clave: sujeto-niño | hipermodernidad | responsabilidad subjetiva | madre | familia | invención

Maisie: the subject of the unconscious beyond the child

Abstract

A six-year-old girl, a troubled split-up and a fight where everything is done to keep with their narcissism. So far, we have a mixture which is very common nowadays. However, the directors show, to those who do not want to keep up with the parent's different ideas that create a trauma to the kid, the possibility of the invention of the subject-kid, that one who, according to Lacan's terminology, stands and does what he has to do with his real. In this short essay, we will try not only to focus on the difficulties that to the kid's psyche mean the lack of significance from the Other, but also the position the kid takes as subject of true right to have a place in the Other.

Keywords: subject-kid | hipermodernism | subjective responsabilitym | mother | family | invention

\section{¿Qué es lo que Maisie sabe?}

Interrogante que parece acercarnos el film y que en cierto punto ha sido faro orientador de este escrito. Sin por ello sostener la ilusión de encontrar una respuesta acabada, esta pregunta despertó a su vez otros interrogantes que permiten acercarnos a una posible lectura de ciertos detalles que hacen del film una obra digna de ser apreciada.

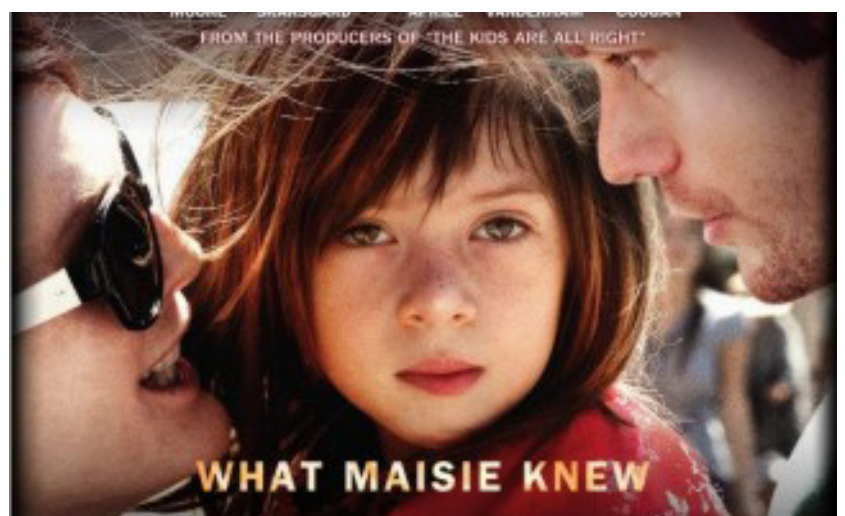

cambio en su vida y es a partir de este real, como diríamos desde el psicoanálisis lacaniano, que tendrá que ir rearmando los retazos de su historia. Tarea nada fácil ya que no hay palabras que sean otorgadas por sus padres para poder nombrar lo que estaba ocurriendo. La separación entonces no es nombrada, solo se le comunica que vivirá con su padre, y antes de que algo de esto le sea aclarado a la niña, sus padres hacen entrar a la vida de Maisie a sus respectivas parejas, nuevamente sin mediar palabra. Beale (Steve Coogan), padre de Maisie, delega en Margo (Joanna Vanderham) la tarea de explicar su presencia en la casa de éste. Luego la madre de la niña (Julianne Moore), sin presentación previa, envía a su nuevo marido a buscar a Maisie al colegio. Entonces la protagonista, antes de comprender bien las implicancias de la separación, debe encontrarse con estas nuevas personas que le son impuestas en su vida. Ahora bien, es tal la guerra ciega que se proponen sostener sus progenitores, que terminan utilizando a sus parejas para que se

* vale_n29@yahoo.com.ar 
hagan cargo precisamente de la "carga", si se me permite jugar con el significante, que significa la propia hija.

Sin embargo, son estos mismos "invasores" quienes acompañan a Maisie en la ardua tarea de significar lo que no fue nombrado, de poner palabras donde solo hubo vacío. Hay allí un encuentro contingente que habilita otras posibilidades para Maisie, un encuentro que habilita el desarme de las certezas de lo que no andaba en la familia de la niña, y permite la incertidumbre sobre la cual se para Maisie para construir algo diferente. Y son ellos quienes por primera vez mantienen un diálogo auténtico con la niña, escuchándola como sujeto y ya no como objeto manipulable. Maisie sabe perfectamente que no son sus padres ni lo serán, pero se permite encontrar un lugar en ellos y desde allí ir construyendo un relato propio.

Y es así, con la sencillez que sólo los niños consiguen, que Maisie ofrece una explicación de su nueva realidad: "mi papa se casó con mi niñera por eso la justicia obligo a mi mama a casarse con Lincoln", y de esta manera hace la presentación que estuvo ausente.

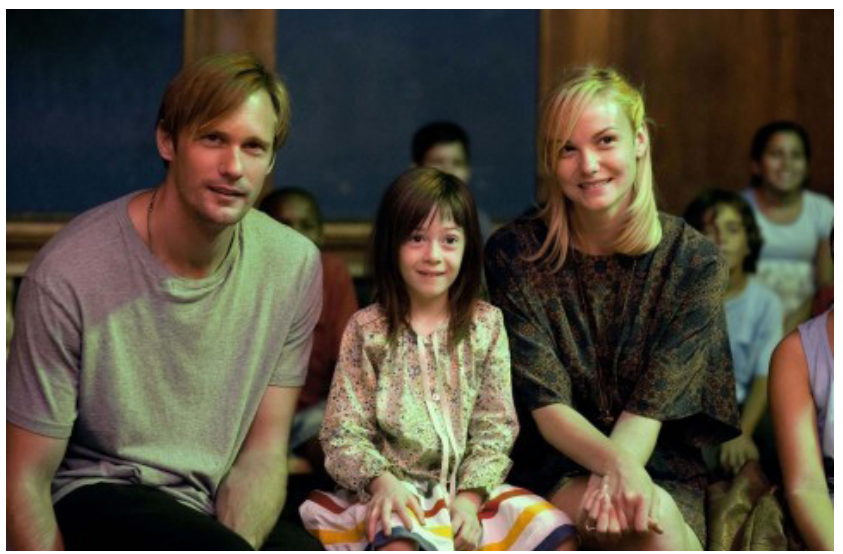

Estos padres no parecen registrar el sufrimiento de su hija, es llamativo que a lo largo de la película ella es llevada de un lado a otro, sin mediar explicación, levantada en el medio de la noche para ser dejada con diferentes personas, veíamos en otras palabras a Maisie al servicio de la inestabilidad parental, manipulada según los tiempos del Otro, esclava del deseo del Otro.

En este punto cabe aclarar que no se trata de la mala intención parental, con ello recordamos el axioma lacaniano de que hagan lo que hagan los padres lo harán mal; de lo que se trata más bien es de ciertas dificultades en estos padres para poder mirar más allá de ellos, el narcisismo parental obstaculiza la posibilidad de que Maisie sea registrada como un sujeto de pleno derecho. Esto no puede ser sin consecuencias, la confusión y el desamparo son algunas de ellas.
La verborragia de sus padres contrasta con las palabras medidas de Margo y Lincoln (Alexander Skarsgard). Ni Beable ni Susanna logran escucharla; de hecho las conversaciones oscilan entre algunas preguntas a Maisie para obtener información sobre el otro progenitor y gritos que parecen funcionar como descargas de ira producto del desborde de cada uno de ellos.

Frente a esto Maisie sólo mira, no habla, no responde desde la lógica parental. Pero son estos ojos los que parecen dejar en claro que ella sabe. ¿Qué es lo que Maisie sabe? Sin decirlo entiende lo que sucede, sabe de las mentiras, sabe de las debilidades de quienes la cuidan, solo que tal vez por momentos elije no verlas. Como cuando refiere a las alergias del padre para no encontrarse con el dolor de la acción de éste.

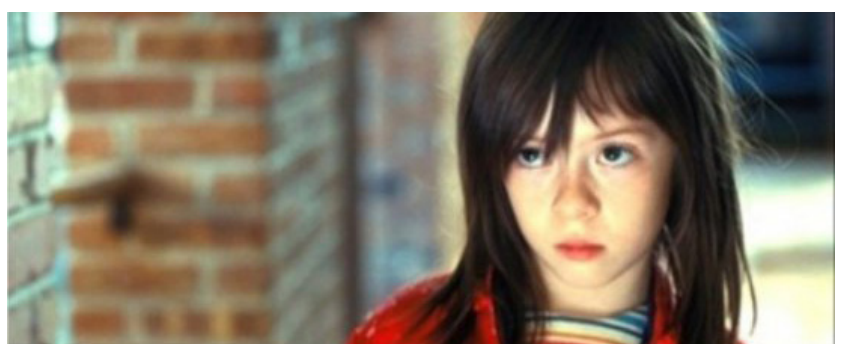

Parece que sólo sus ojos logran poner coto al desborde parental, son los que limitan esa verborragia. Cuando los padres mienten o prometen lo que saben que no cumplirán, son los ojos de Maisie los que evidencia la farsa creada por estos adultos. Allí ellos se conmueven y sólo en ese momento deciden llamarse al silencio. Maisie habla muy poco pero dice mucho, en tanto que les devuelve a través de la mirada la farsa que crearon. Tal vez por esa razón cuando la miran se advierte la culpa en ellos. Como en su padre, en esa escena en la que piensa en llevar a la niña a Inglaterra y hasta en voz alta manifiesta su intención de perjudicar a su ex pareja, pero los ojos de Maisie parecen disuadirlo.

Susanna, por su parte, nos lo muestra cuando advierte el miedo en los ojos de Maisie. Esta es la primera vez que su madre la escucha y respeta sus tiempos, sus decisiones, a diferencia de lo que la vemos hacer a lo largo de todo el film, marcado por promesas incumplidas. Solo en esa escena parece comprender que sus tiempos no siempre coinciden con los de su hija y es allí donde logra considerarla como un sujeto diferente a ella, permitiéndole quedarse para poder viajar en barco como Maisie quería, lo cual al principio había considerado algo sin importancia.

Tal vez esto también sea posible debido a que Maisie por primera vez dice que no a la exigencia e insensatez materna. Este posicionamiento de la niña recuerda la en- 
señanza de Lacan respecto del niño como sujeto de pleno derecho: "la insondable decisión del ser ¿Es posible en este punto pensar a Maisie en términos de grande personne? Recordemos que para el psicoanálisis lacaniano lo que separa al niño de la persona mayor no es la edad ni el desarrollo ni la pubertad, como bien explica Eric Laurent, lo que hace a un sujeto grande personne es la posición de quien se hace responsable de su goce. Y para ello el niño deberá haber hecho el recorrido para separarse, para que su cuerpo no sea el condensador de goce de su madre (Laurent, 1999).

\section{Los tiempos hipermodernos}

No es posible dejar de considerar cierta audacia de los directores para mostrar las características epocales; y lo hacen con una sutileza digna de reconocimiento ya que no les hace falta convocar a ningún aparato tecnológico para dejar en evidencia los cambios propios de estos tiempos. Nos muestra aquello que Lacan anticipó a lo largo de su enseñanza, la caída del Nombre del Padre, y que encuentra resonancias en la visión de Lipovetsky (2003): la cultura hipermoderna está marcada por el debilitamiento del poder regulador de las instituciones y la autonomización de los actores que a su vez eran reguladores de la familia, la religión, los partidos políticos, el debilitamiento del orden simbólico, de los grandes relatos, de las ideologías. Los directores dejan en claro que el padre moderno no es el padre del Edipo freudiano, sino un padre más bien humillado, que debe traer el sueldo a la casa y mientras lo haga bien podría desaparecer, es decir, no importa tanto si está o no.

Ahora bien, lejos de generar sostén y seguridad, esa movilidad y autonomía se traduce en un incremento inquietante de la ansiedad, la depresión y una desestabilización del sujeto, quien aparece más desolado, no tiene norte, esta desorientado, no le encuentra sentido a su vida. Como explica Jorge Assef (2003), esto conlleva al individualismo autogestionado y a la autoconstrucción de identidades que tiende a realizarse a través del consumo, y al retomar la tesis de Lipovetsky, nos dice que cada sujeto entonces es libre de construir, a la carta, su entorno personal, pero esta ilusión de completud conlleva a la pérdida de los lazos y las dificultades en el encuentro con el Otro.

De esta manera se presentan Susanna y Beadle, quienes hacen uso de sus nuevas parejas como si fueran descartables, la elección pareciera estar marcada por la pro- ductividad y la eficacia o no que estas parejas garanticen. En otras palabras, si sirven para cuidar a Maisie y además para potenciar la guerra que ambos emprendieron.

En este sentido, el film deja también en evidencia el tratamiento que la hipermodernidad hace del tiempo. La brevedad y la eficacia como significantes amos imposibilitan el tiempo para detenerse, para reflexionar; por el contrario, hay que seguir, no mirar atrás, no esperar. Y así es arrebatado el tiempo de Maisie, quien es arrastrada de un lado al otro de acuerdo a las necesidades de los adultos. Y por supuesto tampoco hay tiempo para explicaciones, para duelos, para escuchar o preguntarle al otro semejante como se siente.

Sólo Margo y Lincoln parecen escuchar el pedido silencioso de Maisie y respetan sus tiempos. Así lo hace Margo cuando ayuda a Maisie a pegar las flores que su mamá le había regalado y el padre decide tirar. Y Lincoln por su parte, decide dejar descansando a Maisie cuando ésta tiene fiebre en vez de llevarla cuando Susanna lo disponía, aceptando las consecuencias de volver sin la niña. Ellos se permiten priorizar lo que la niña necesita por encima de las necesidades de sus padres.

\section{¿La madre como único parteneire?}

El film nos muestra una madre que a pesar de casarse nuevamente no quiere un padre para Maisie, de hecho se encarga de castrarlo permanentemente. Sólo quiere una niñera, un señor de los mandados, alguien que le sirva, como ella le dice a su hija respecto de Lincoln: “...sólo intentaba facilitarnos las cosas". Y no quiere un padre para Maisie en tanto no tolera dejar de ser imprescindible para su hija. Teme perder su amor, teme perder su lugar en el otro. Lógica imaginaria diríamos con Lacan (1946), donde sólo hay lugar para uno, con lo cual si Maisie quiere a Lincoln, para Susanna significa que Maisie deje de quererla a ella. Y lo deja en claro en aquella escena en la que se molesta cuando Lincoln aplaude el cuento de Maisie: ¿“...soy invisible?”, o cuando reclama a su hija: ¿"ya no te agrado?", demanda de amor que no admite insatisfacción alguna. La ley caprichosa de la madre, como enseña Lacan (1992) respecto del deseo materno, es muy bien ilustrada por los directores.

Adela Fryd sostiene que cuando la madre es el único partenaire, “...el sujeto corre el riesgo de caer en la trampa de la alternativa: o de asumir los votos maternos sobre su persona o de oponerse, lo que equivale a decir toma su mandato como brújula” (Berkoff et al, 2014). 
En este sentido me preguntaba si Maisie había caído en esta trampa. Lejos está la intención de responder con certezas imposibles, pero pienso que la niña logra correrse de esa encrucijada. En un primer momento, en las primeras escenas la vemos alienada a las exigencias maternas. Sin embargo, la desestabilización materna no desestabiliza a Maisie, la confusión de la niña resulta más bien el motor para lograr construir una ficción propia que no es en oposición al mandato materno. De hecho, la escena final da cuenta de que Maisie no se maneja desde el rencor oposicionista, que sólo reflejaría más alienación, sino que logra hacer su propio arreglo, vérselas con el real que le tocó, con esos padres con sus dificultades pero marcando una posición propia. Enseña así a su madre que no debe tener miedo de perderla: ¿"...sabes quién es tu madre? pregunta Susanna, a lo que Maisie responde: "sí, tú".

\section{De la reproducción del decir familiar a la invención propia}

En el texto "La familia", Lacan sostiene que ésta desempeña un papel primordial en la transmisión de la cultura, en tanto funciona instaurando la educación inicial, la represión pulsional y la adquisición de la lengua materna.

Y nos lo recuerda en "dos notas sobre el niño" cuando resalta la función de la familia como lugar de transmisión que interviene en la constitución subjetiva, que "implica la relación con un deseo que no sea anónimo" (Lacan, 1991, p.56).

En este sentido, pensar en la familia es pensar en esa particular forma en que el lenguaje se inscribe en el sujeto, la manera en que el discurso del Otro deja marcas, genera deseos, ideales y por qué no también malentendidos. El malentendido como legado estructural de la condición propia del ser hablante. Dirá Lacan:

No hay otro trauma de nacimiento que nacer como deseado. Deseado, o no: de lo mismo da igual, ya que es por el hablante ser. El ser hablante en cuestión se reparte, por lo general, en dos hablantes. Dos hablantes que no hablan la misma lengua. Dos que no se escuchan hablar.
Dos que no se entienden, sin más. Dos que se conjuran por la reproducción, pero de un malentendido cabal, que vuestro cuerpo hará pasar con a dicha reproducción (Lacan, 1980).

Entonces, si bien Lacan destaca el valor simbólico de la familia, como ordenadora de la cultura, también resaltará su función de transmisión del malentendido fundamental, siendo así la familia la que nos habla a través de nuestras palabras. En tanto sujetos hablantes somos esclavos del discurso del Otro, ya que no hay sujeto sin el Otro que le dé un lugar en el intervalo de su falta. En otras palabras, el niño que viene al mundo tendrá que emprender la difícil tarea de prenderse de los significantes que el Otro le otorgue para poder existir. Ahora bien, ¿es la mera reproducción acaso el único destino posible? Y aquí me interesa destacar el valor de las palabras de Miller en el ultimísimo Lacan cuando insiste en no conformarse con ser hablado por la familia, sino en librarse, luego de haberlas recorrido, de las escorias heredadas del discurso del Otro (Miller, 2012). El sujeto es entonces en función de haber aceptado primero el sentido que le otorga el Otro, pero también de haber podido separarse de éste y jugar sus propias cartas en el deseo.

Es en mi opinión lo que nos enseña Maisie, quien inventa una manera particular de arreglárselas con ese real de su familia. Lejos de reproducir un discurso victimizante, se responsabiliza de su real y hace algo con eso. La última escena da cuenta de ello, el júbilo de la niña que corre para subir al barco, tal vez no sea sólo un barco más el que ella decide tomar...

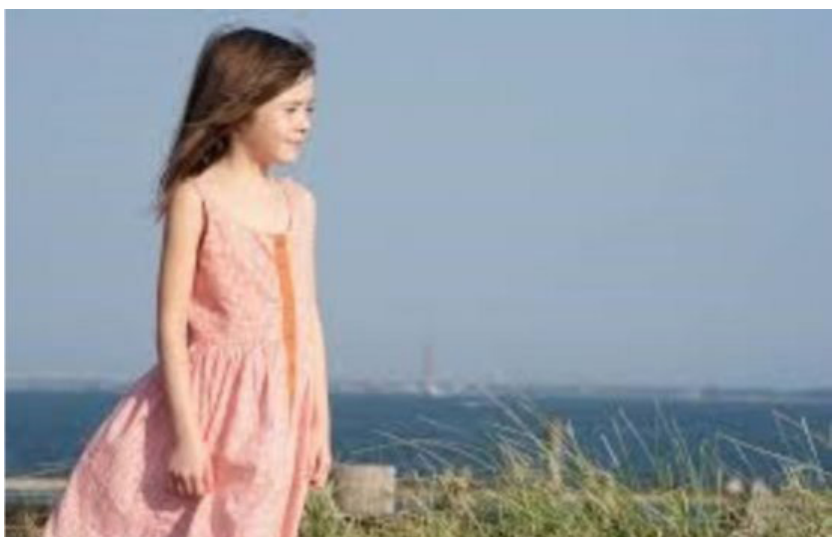

\section{Referencias:}

Assef, J. (2013) “La subjetividad hipermoderna: una lectura de la época desde el cine, la semiótica y el psicoanálisis.” Buenos Aires: Grama Ediciones.

Berkoff, M. et al (2014) “El niño y el trauma. Interrogantes de la última enseñanza de Lacan en la clínica con niños” en Virtualia Revista Digital de la Escuela de la Orientación Lacaniana, Noviembre 2014. N²9. Disponible en http://virtualia.eol.org.ar/029/Vir...

Lacan, J. (1980) “El malentendido” en El Seminario de Jacques Lacan. Libro 27. Obtenido el 28 de febrero de 2017 en file://C:/ Users/Usuario/Downloads/Jacques\%20Lacan\%20-\%20El\%20malentendido\%20(10.06.1980).pdf 
Lacan, J. (1946) “El Estadio del espejo” en Escritos I. Buenos Aires: Siglo Veintiuno Editores.

Lacan, J. (1977) “La familia.” Buenos Aires: Homo Sapiens.

Lacan, J. (1991) “Dos notas sobre el niño” en Intervenciones y textos 2. Buenos Aires: Manantial.

Lacan, J. (1992) “El reverso del psicoanálisis”, Seminario 17. Buenos Aires: Paidós.

Laurent, E. (1999) “Hay un fin de análisis para los niños”. Buenos Aires: Colección Diva.

Lipovetsky, G. (2003) “Metamorfosis de la cultura liberal”. Barcelona: Anagrama.

Miller, J-A. (2012) “El ultimísimo Lacan”, Curso de la Orientación Lacaniana. Buenos Aires: Paidós. 